\title{
AN ANTI-POLLUTION DEVICE FOR USE WITH THE JACKSON REES MODIFICATION OF AYRE'S T-PIECE
}

\author{
D. J. STEWARD, M.B., B.S., F.R.C.P.(C)
}

POLLUTION OF THE OPERATING ROOM ATMOSPHERE by anaesthetic gases has recently attracted much attention in medical literature. ${ }^{1,2}$ Possible adverse effects on medical personnel which have been suggested range from inereased irritability and headaches, to increased abortion rates, and even to effects on the mortality patterns amongst professional groups. ${ }^{3}$

Non-rebreathing circuits are major contributors to this pollution. The T-piece, in which a high fow rate of fresh gas is essential to the performance of the system, must be considered a major source of pollution. The advantages of the $T$-piece are such that it is widely used in paediatric anaesthesia practice.

The equipment described below collects gases from the expiratory limb of the Jackson-Ilees modification of Ayre's T-piece system and prevents contamination of the atmosphere of the operating room.

\section{EOUIPMENT}

The equipment essentially consists of a "Bag in a Bottle" (Figure 1). A standard M.I.E. ${ }^{\dagger} 750 \mathrm{ml}$ bag is mounted in a transparent "Perspex" box of inside dimensions 9 by 3 by 5 inches. The mount for the bag is incorporated into the proximal end of the box, which forms a detachable lid. In this lid four ${ }^{4}$-inch holes are drilled. The distal end of the box has a centrally placed stem of ${ }^{\prime \prime}$-inch inside diameter which is connected to a suction outlet. When suction is applied to the outlet, a stream of air is drawn through the box and anaesthetic gases escaping from the open-ended bag are thus removed and prevented from contaminating the atmosphere. It is noted that this equipment is applicable only when the patient is breathing spontaneously. A second $750 \mathrm{ml}$ bag must be immediately available should artificial ventilation be necessary.

\section{Discussion}

This equipment has been found effective in removing exbaled anaesthetic gases from the Jackson Rees modification of the Ayre's T-piece. It is recognized that, in the present form, it is not applicable to the patient requiring controlled ventilation and thus the problem of their removal is avoided.

The apparatus does not in any way affect the function of the T-piece circuit and during use there is no change in pressure within the box. Ventilation can be easily assessed visually by observing movement of the bag. If it is necessary to ventilate

- Department of Anaesthesia, The Hospital for Sick Chiddren, Toronto, Ontario.

† Medical Industrial Equipment.

$$
670
$$

Canad. Anaesth. Soc. J, vol. 19, no, 6, November 1972 


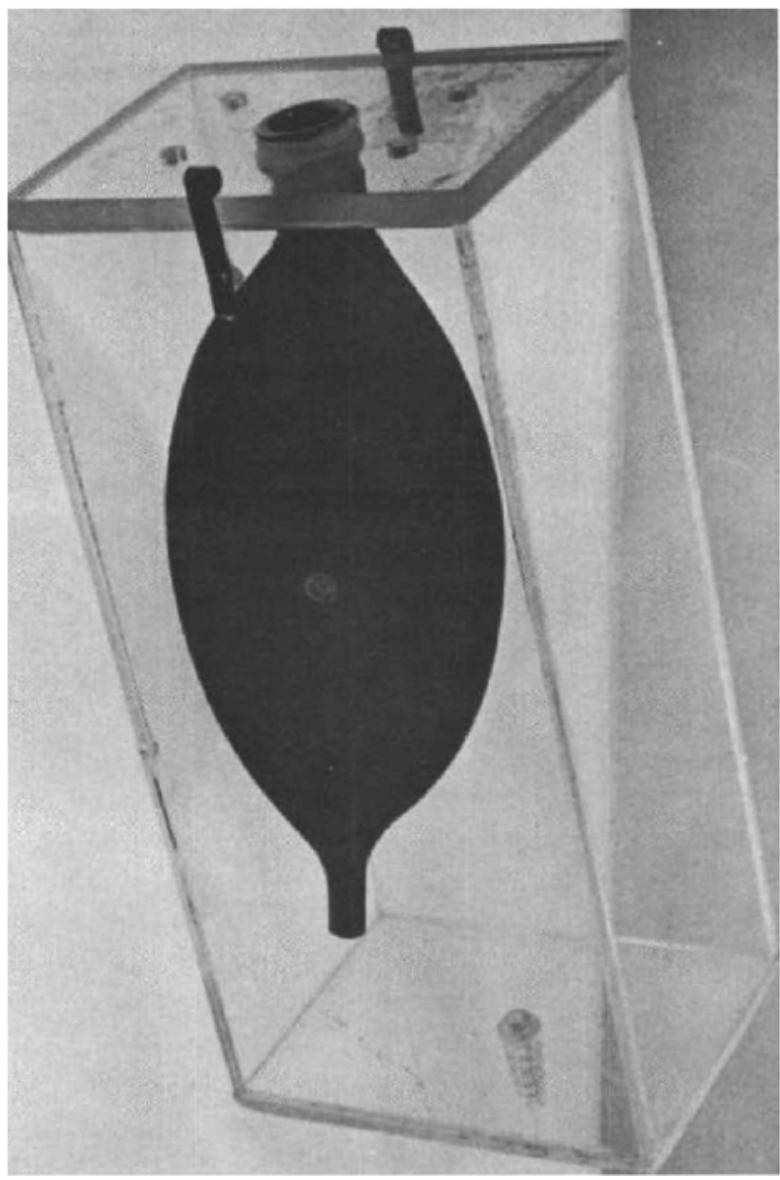

the patient manually for any reason, another $750-\mathrm{ml}$ bag must be connected to the expiratory limb of the system.

\section{SUMMARY}

Apparatus is described to collect gases from the expiratory limb of a T-piece anaesthetic circuit and so to prevent atmospheric pollution of the operating room.

\section{REFERENCES}

1. Corbetr, T.H. \& BALL, G.L. Chronic exposure to methoxyflurane: a possible occupational hazard to anesthesiologists. Anesthesiology $34: 532$ (1971).

2. LINDE, H.W. BRucr, D.L. Occupational exposture of anesthetists to halothane, nitrous oxide and radiation. Anesthesiology 30:363 (1969).

3. Bruce, D.L., Eide, K.A., LindF, H.W. \& Eckenfoff, J.E. Catuses of denth anong anesthesiologists: a 20-year survey. Anesthesiology $29: 565$ (1968). 